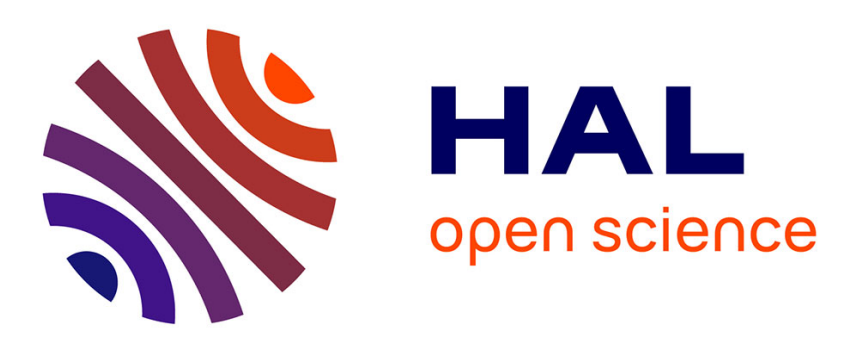

\title{
Design and fabrication of a continuously tuned capacitor by microfluidic actuation
}

\author{
Nizar Habbachi, Hatem Boussetta, Ali Boukabache, Mohamed Adel Kallala, \\ Patrick Pons, Kamel Besbes
}

\section{- To cite this version:}

Nizar Habbachi, Hatem Boussetta, Ali Boukabache, Mohamed Adel Kallala, Patrick Pons, et al.. Design and fabrication of a continuously tuned capacitor by microfluidic actuation. Journal of Micromechanics and Microengineering, 2018, 28 (3), 10.1088/1361-6439/aaa63a . hal-01852455

\section{HAL Id: hal-01852455 \\ https://hal.laas.fr/hal-01852455}

Submitted on 1 Aug 2018

HAL is a multi-disciplinary open access archive for the deposit and dissemination of scientific research documents, whether they are published or not. The documents may come from teaching and research institutions in France or abroad, or from public or private research centers.
L'archive ouverte pluridisciplinaire HAL, est destinée au dépôt et à la diffusion de documents scientifiques de niveau recherche, publiés ou non, émanant des établissements d'enseignement et de recherche français ou étrangers, des laboratoires publics ou privés. 


\title{
Design and fabrication of a continuously tuned capacitor by microfluidic actuation
}

\author{
Nizar Habbachi ${ }^{1}$, Hatem Boussetta ${ }^{1}$, Ali Boukabache ${ }^{3}$, Mohamed Adel Kallala ${ }^{1}$, Patrick \\ Pons $^{3}$, Kamel Besbes ${ }^{1,2}$
}

\author{
${ }^{1}$ Microelectronics and Instrumentation Laboratory, Faculty of Sciences of Monastir, 5000 Monastir, University \\ of Monastir, Tunisia. \\ ${ }^{2}$ Center for Research on Microelectronics \& Nanotechnology, CRMN Sousse TechnoPark. \\ ${ }^{3}$ Laboratory for Analysis and Architecture of Systems, CNRS, LAAS, 7 avenue du Colonel Roche, 31077 \\ Toulouse, France.
}

E-mail: habbachinizar@yahoo.fr

\begin{abstract}
This paper presents the design and the fabrication of a continuously tunable RF MEMS capacitor using micro fluidics as a tuning parameter. The impedance variation principle is based on the modification of the capacitor gap permittivity produced by the presence of deionized water and its displacements in a channel inserted between electrodes. In addition, the electric field distribution changes in equiponderant way according to the DI water positions in the channel. This change modifies the capacitive coupling, the stored energy and consequently the self-resonant frequency. The fabrication process is based on two parts: metallic paths having a spiral form, and obtained by electroplating a $7 \mu \mathrm{m}$ thick gold layer to constitute electrodes; and fluidic channels, realized by super imposing two SU-8 films. The measurements show a non-linear variation of the capacitor value according to the water positions. The tuning range is very large, reaching up to $4650 \%$ for the capacitance, and $335 \%$ for the resonant frequency. However, the quality factor reaches $\mathrm{Q}_{\max }=79$ at $550 \mathrm{MHz}$ if the capacitor is empty and decreases with the fluid displacements to $\mathrm{Q}_{\min }=3.13$.
\end{abstract}

Keywords: Fluidic actuation, RF MEMS, Tunable capacitor, CPW, RF characterization.

\section{Introduction}

Advances in micro technologies have improved the performances of broadband radio frequency circuits. Several studies were performed to increase the tuning-range, the quality factor and the resonant frequency of different devices used in radio frequency circuits. Among them, RF MEMS capacitors have emerged with high performances; they are largely used to replace conventional varactor. Various actuation mechanisms were presented to control RF MEMS capacitors in order to obtain substantial modifications of the gap or the surface between electrodes. Electrostatic actuation is the most reported because of its low power consumption, fast response time, and ease of control. 
The first reported RF MEMS variable capacitor [1] uses electrostatic actuation to tune the gap between electrodes. The measured value of the capacitance exhibits a low tuning range $\operatorname{Tr}=16 \%$, limited by pull-in effect. The proposed solution is to introduce a third electrode to control its displacements [2]-[4]. Therefore, the tuning range of these capacitors is improved and reported results can reach $\operatorname{Tr}=300 \%$. In other structures, electrostatic actuation is used to tune the surface between electrodes. The common feature of these structures is that both electrodes are fragmented into several interdigitated fingers and controlled by a comb-drive. Hence, the free electrode is suspended above the substrate and moves vertically with respect to the fixed electrode [5] [6]. The measured capacitance shows a nominal capacitance of $1.4 \mathrm{pF}$ and a tuning range of $\mathrm{Tr}=10 \%$ at $8 \mathrm{~V}$. Another method of surface variation modifies laterally the angle between both electrodes [7]. The stationary electrode is embedded in the center of the structure that enables lateral rotation of the free electrode. This method allows a tuning range of $\operatorname{Tr}=110 \%$ for a control voltage of $11 \mathrm{~V}$.

In these different architectures, the variation of RF MEMS capacitor is provided by the movement of free electrode. This shift requires long beams and large suspension arms to support the weight of the metallic mobile electrode. Therefore, to ensure an accurate variation, it is necessary to increase the control system size that increases the response time and the parasitic effects. An alternative solution is to fix the two plates of the capacitor and vary the dielectric position [8]. The results show a significant amelioration of the quality factor until $\mathrm{Q}=290$ but the tuning range of capacitance remains low $\operatorname{Tr}=$ $40 \%$. To increase the capacitance variation, two comb drives have been used [9], which allow to control accurately the dielectric movement, giving a variation of $\operatorname{Tr}=367 \%$.

Knowing that the dielectric permittivity influences the impedance of capacitor, the dielectric plate displacement between its electrodes can give large variations around its nominal capacitance. In addition, it is expected that the radio frequency (RF) performances of the device to be good, which is why we choose this mode of variation of our RF MEMS capacitor and design it consequently. In our study, we used deionized water as a dielectric circulating between metallic electrodes. On the one hand because it has a high permittivity $\varepsilon=81$, and on the other hand it is easy to manipulate. In the second section of this paper, we discuss the principle of variation of the capacitance, its effect on the distribution of electric field lines and the simulation results of the capacitor performances. To illustrate our theoretical approach, we present in the two last sections the principal manufacturing steps of our devices, the measurement results and finally the comparison between experiments and simulation.

\section{Theoretical approach:}

\subsection{Principle of variation:}

The $3 \mathrm{D}$ view of the capacitor device intended for fluidic actuation and the cross section are presented in Figure 1(a-b). The principle of variation of capacitance, and consequently the tuning of the resonant frequency, is based on the modification of the electric field by the displacement of deionized water 
between electrodes. The positions of DI water are quantified by their volume as shown in figure 1(ch): POS1 $=4.6 \mathrm{~nL}$, POS2 $=13 \mathrm{~nL}, \mathrm{POS} 3=26 \mathrm{~nL}, \mathrm{POS} 4=43.8 \mathrm{~nL}$, POS5 $=66 \mathrm{~nL}$, POS6 $=92.9 \mathrm{~nL}$. As we shall see, the distribution of electric field lines will depend essentially on the geometry of the capacitor, the nature of materials and the positions of deionized water in microfluidic channels. All these parameters will be used in order to optimize the fabrication process and to enhance the capacitor permittivity by balancing between DI water and air.

\section{(Insert figure 1)}

By using the classic formula of capacitance, it can be observed that:

$\frac{C-C 0}{C 0}=\frac{\varepsilon_{F}-\varepsilon_{0}}{\varepsilon_{0}}$

Hence, the expected tuning range of our capacitor depends only on the values of $\varepsilon_{\mathrm{F}}$ (fluid permittivity) and $\varepsilon_{0}$ (air permittivity, $\sim 1$ )

In our case, we used DI water: it presents a high permittivity close to 81 , allowing an important tuning range of capacitance that can reach theoretically $\operatorname{Tr}=8000 \%$.

All the used dielectric materials affect the capacitance ratio, both the BR33 substrate and the Su- 8 walls. Nevertheless, the classic formula allows calculating only the capacitance value between two electrodes and does not consider the materials interaction. The advantage of this formula is to highlight the influence of DI water on capacitor tunability.

\subsection{Structure design:}

To design and simulate the capacitor/microfluidic interactions, materials, dimensions and some functionality have been chosen so that the projected device can be realizable by using micro technologies.

Firstly, the selected substrate is a Borofloat 33 glass having a thickness of $500 \mu \mathrm{m}$, and presenting interesting parameters: a low permittivity $\varepsilon=4.6$ and a near zero dielectric loss $\tan \delta=0.0037$ that can be important for RF uses. The Au electrodes can have a $7 \mu \mathrm{m}$ thickness, having high conductivity $\sigma=$ $41.10^{6} \mathrm{~S} / \mathrm{m}$ and good resistance to water corrosion. For liquid circulation between these electrodes, SU-8 photo-resist will be used to obtain fluidic channels having $50 \mu \mathrm{m}$ of height, $200 \mu \mathrm{m}$ of width, and a $20 \mu \mathrm{m}$ thickness for the cover. The dielectric properties of cross-linked SU-8 films are wellknown [10]: permittivity $\varepsilon=2.85$ and dielectric loss $\tan \delta=0.04$, allowing us to simulate the RF behavior of the device. The expected inner diameter of the capacitor will be $200 \mu \mathrm{m}$ with a spiral width of $15 \mu \mathrm{m}$ and a $20 \mu \mathrm{m}$ gap between electrodes. 


\subsection{Electric field distribution:}

We have studied the variations of the electric field distribution in the device and its dependence on the DI water at 550MHz using FEM tool. The figure 2 shows the results for two extremely states: the capacitor is empty (Fig2.a) and fully filled with DI water (Fig2.b).

\section{(Insert figure 2)}

The cross section of the capacitor without liquid (Fig.2 (a)) shows that the maximum electric field is prevailing in the microchannels separated by SU-8 walls. In addition, the electric field is maximum at the excitation RF port 1 and penetrates into the dielectric substrate. In the second case, where the capacitor is fully filled with DI water (Fig.2 (b)), the electric field is maximum at the two excitations $\mathrm{RF}$ ports and is distributed in equiponderant way in the device. Furthermore, the microchannels become deprived from electric field, and only a residual part remains between capacitor electrodes. It is obvious that the presence of DI water increases the permittivity in the microchannels and thus electric field flees to BR33 substrate. One can observe that the fluid present in channel acts as a containment medium of the electric field prevailing between the electrodes. Therefore, we choose the circular geometry of the fluidic channel to ensure a maximum quality factor. In addition, we designed a large fluidic channel that leads to a wide tuning range. Indeed, we have investigated the microchannel width effect on the tuning range. We have introduced the possibility to adapt the microchannel width, by modifying it from $100 \mu \mathrm{m}$ to $200 \mu \mathrm{m}$ with a $10 \mu \mathrm{m}$ step for two states: when the capacitor is empty and when it is fully filled with water. Then, we have calculated for every step the tuning range, and the result is shown in Figure 3(a).

\section{(Insert figure 3)}

As we can see, the tuning range depends on microchannel width and reaches its maximum for the higher value of microchannel width. In addition, we have optimized the capacitor design based on the electrodes width at $550 \mathrm{MHz}$ using the same FEM tool. We have varied the width between $5 \mu \mathrm{m}$ and $25 \mu \mathrm{m}$ when the capacitor is empty. The quality factor and the resonant frequency variations are shown in Figure 3(b). The quality factor curve is not a linear function of the electrodes width: it increases from $\mathrm{Q}=95$ until to reach $\mathrm{Q}=128$ at $\mathrm{W}=17 \mu \mathrm{m}$; it decreases at $\mathrm{W}=25 \mu \mathrm{m}$ until $\mathrm{Q}=121$. Otherwise, the frequency decreases linearly from $3 \mathrm{GHz}$ to $2.57 \mathrm{GHz}$ when the electrodes width varies from $5 \mu \mathrm{m}$ to $25 \mu \mathrm{m}$. These results demonstrate the importance of the electrodes width on the capacitor performances.

\subsection{Capacitance variations:}

We have used the same FEM tool to simulate the behavior of the device constituted by the microsystem capacitor/DI water, in the range of frequency from $10 \mathrm{MHz}$ to $10 \mathrm{GHz}$. The variations of 
the capacitance value for the six positions of water are shown on figure 4(a). We can observe that the global behavior is the same, but there is a large and direct influence by the water quantity in channels.

\section{(Insert figure 4)}

When the capacitor is empty (POS0), the capacitance value is minimum; with fluid progression (POS1 to POS6) it increases continually. This evolution seems linked to the high permittivity value of deionized water $(\varepsilon=81)$ which increases the coupling between electrodes: the capacitance value is maximal when the channel is fully filled (POS6). However, this desired evolution is followed by a drastic decrease of the quality factor as shown in fig. 4(b): it reaches its maximum value when the capacitor is empty (POS0) and it falls sharply with the position of water.

\subsection{Coplanar waveguide responses:}

\subsubsection{Overview of CPW:}

Coplanar waveguide (CPW) on dielectric substrate are introduced in 1969 [11] and they are commonly used in microwave monolithic integrated circuits (MMICs) [12]. Multitudes CPW components have emerged with high performances: CPW inductors [13-15], CPW capacitors [16-17], microstrip lines and Slotlines [18]. CPW components allow fast and inexpensive fabrication and characterization of RF circuit such as filter, coupler, and amplifier [19].

CPW structures are said lossless if the incident wave is completely transmitted to the output. The wave transmission is limited at the input by reflection loss and at the output by insertion loss. The resonant frequency is achieved when return loss is minimal and incident wave crosses the structure.

\subsubsection{Tunable CPW:}

For broadband RF applications, CPW components uses RF MEMS technics in order to ensure large variation [20-23]. In a previous work, our team have designed and fabricated a microfluidically tunable microstrip waveguide using a buried microchannel inside the substrate [24]. The presence of deionized water beneath the resonant stub modify the effective permittivity of the substrate and thus disturb the coupled electric field [24]. The maximal frequency variation reaches $20 \%$ and depends on the permittivity value of dielectric liquid and his position [24]. Indeed, the response of waveguide depends on geometrical and dimensional parameters of transmission lines and the physical parameters of the whole medium. In our case, the dual circular geometry increases the coupled electric field between two metallic transmission lines and the microchannel covers the totality of medium where prevailing electric field.

The fig. 5(a) shows that the return loss curves frequency varies between $0.7 \mathrm{GHz}$ and $4 \mathrm{GHz}$ for the six fluid positions. It is obvious that resonant frequency is maximal when the capacitor is empty and more that the deionized water penetrates in the structure more the resonant frequency decreases. 
In figure 5(b) are reported the curves of the insertion loss according to the frequency for the various positions of the deionized water. It is clear that the frequency band is larger when the capacitor is empty and decreases according to the deionized water filling.

\subsection{Overall benefits:}

To better show the influence of the fluidic positions and consequently its presence, we have collected the capacitance values and the quality factor at $550 \mathrm{MHz}$ and reported the results in figure 6: it can be observed that the capacitance varies largely: from $\mathrm{C}_{\min }=0.672 \mathrm{pF}$ when the capacitor is empty, to $\mathrm{C}_{\max }=28.2 \mathrm{pF}$ when it is entirely filled with deionized water.

\section{(Insert figure 6)}

In addition, we can conclude that the tuning range is greater than $\operatorname{Tr}=4090 \%$. However, we also observe that the quality factor decreases from $\mathrm{Q}_{\max }=125$ when the capacitor is empty to $\mathrm{Q}_{\min }=2.7$ when the capacitor is full. For the resonant frequency variations, we have collected the minimum of return loss at each fluid level, and it can be observed in figure $6(\mathrm{~b})$ that the resonant frequency varies continuously from Fres $=2.75 \mathrm{GHz}$, when the capacitor is empty, to Fres $=680 \mathrm{MHz}$ when it is full of deionized water. Hence, we obtain a wide band of resonant frequency in the order of $300 \%$.

\subsection{Dielectric constant effect:}

In order to study the frequency dependence of DI water's dielectric constant, we have varied the relative permittivity $\left(\varepsilon_{r}\right)$ between 10 and 100 , and the loss tangent $\left(\tan \delta=\frac{\varepsilon_{r}^{\prime}}{\varepsilon_{r}} ; \varepsilon_{r}=\right.$ real part, $\varepsilon_{r}^{\prime}=$ imaginary part) between 0.01 and 0.1 . The obtained results show the effect of $\tan \delta$ on return loss response for different $\varepsilon_{r}$ values when the capacitor is fully filled with DI water (figure. 7(a)):

\section{(Insert figure 7)}

It is clearly seen that $\tan \delta$ affects only the gain amplitude and the return loss curves are minimal for $\tan \delta=0.01$. Furthermore, the $\varepsilon_{r}$ changes the bandwidth and the frequency resonance of return loss responses. The bandwidth is larger and the frequency is higher for $\varepsilon_{r}=10$. The figure.7 (b) illustrates the frequency variation in response of $\varepsilon_{r}$ : the maximal value $\mathrm{F}_{\max }=1.65 \mathrm{GHz}$ is obtained for $\varepsilon_{r}=10$ and becomes minimal $\mathrm{F}_{\min }=0.62 \mathrm{GHz}$ for $\varepsilon_{r}=100$. The total variation of frequency reaches $166 \%$ in response to the fluid permittivity variations. Indeed, the polarization of DI water's charged dipoles 
depends to the frequency of applied electric field. At low frequencies, these dipoles follows efficiently the direction of the electric field. When the frequency increases, these dipoles lose partially their ability to follow the electric field variations, and thus the frequency response of the structure decreases. Furthermore, the insertion of DI water increases the permittivity between two electrodes and thus increases the capacitance value.

\section{Fabrication process:}

The dual circular geometry has been used in microfluidics structures to control magnetic beads [25] and to ensure the inductor variation [26]. This type of geometry is based on a single metal layer that facilitates masks alignment, reduces electrical losses, and minimizes manufacturing cost. Moreover, spiral coils are completely covered by fluidic channel that increases their capacitance variations. We present in figure 8 the photography of our manufactured device: (a) top view of the global structure; (b) terminal input port; (c) cross section of the entire transversal structure with microfluidic channels.

\section{(Insert figure 8)}

The fabrication process can be divided into two important parts: fabrication of electrodes and structuration of SU8 photoresist to obtain fluidic channels.

\subsection{Electrodes metallization:}

The process starts by depositing a Ti/Cu layer necessary to enhance, in the next step, the attachment of the metal coil to the substrate. Then a layer of positive photoresist AZ4562 is deposited and structured by a photolithography process: it serves as a mold for the electrodeposition of $7 \mu \mathrm{m}$ Au layer. After ensuring gold structure homogeneity, AZ4562 molding layer is removed by chemical etching and the adhesion layer of $\mathrm{Ti} / \mathrm{Cu}$ is released by wet etching.

\subsection{Microfluidic channel:}

Among its intrinsic qualities, the polymer SU-8 presents a particular high aspect ratio, and it is widely used in domains connected to microfluidic and its applications. In our structure, this photoresist is used to realize the channels of water circulation and to cover them.

For this first realization, we have used only two levels of SU-8 layers. The first one constitutes the circular geometry of the channel of $50 \mu \mathrm{m}$ height. This layer is obtained by spin coating of a $4 \mathrm{ml}$ of SU-8 3050 resin, which is then annealed in three phases. The initial temperature is set at $65^{\circ} \mathrm{C}$ for 1 min then it will rise to $95^{\circ} \mathrm{C}$ with a rate of $10^{\circ} \mathrm{C} / \mathrm{min}$. The structure is maintained at this temperature value during $7 \mathrm{~min}$, and finally decreased, with the same rate, until $20^{\circ} \mathrm{C}$. The resin is then insulated under UV and cross-linked during a Post-Exposure-Bake (PEB). The cover layer is formed by an SU-8 dry film of $20 \mu \mathrm{m}$ height; it is laminated on the top of channels network, at a speed of $\mathrm{v}=1 \mathrm{~m} / \mathrm{min}, 2$ 
bar and $65^{\circ} \mathrm{C}$. The last step, to finalize the device, is to open the access holes in order to connect it to the water reservoir.

\section{Characterizations:}

The RF measurements are performed by using an Agilent 8510 network analyzer and a Microtech GSG probes. The frequency range from $10 \mathrm{MHz}$ to $10 \mathrm{GHz}$ allows testing the devices in the RF domains. These electrical characterizations are performed before and after filling the capacitor channels with deionized water. For the fluidic actuation, we have used automated syringe and the global measurement platform is described in figure 9:

\section{(Insert figure 9)}

This method is commonly employed in microfluidic tests but, for largest implementations, it is possible to integrate miniature pumps. The maximum flow rate of fluidic actuation reaches 222.5 $\mathrm{mL} / \mathrm{min}$ with a minimum dosing volume step of $203.45 \mathrm{pL}$. The total volume of microchannels is about $93 \mathrm{~nL}$ and the capacitor can be tuned at $2.4 \mu \mathrm{s}$. This tuning speed is related to the actuation system technics and could be ameliorated by using an enhanced automated syringe pump.

\subsection{Measurement results:}

The capacitance $\mathrm{C}(\mathrm{f})$, the quality factor $\mathrm{Q}(\mathrm{f})$ and the return loss were calculated by using the following equations:

$$
\begin{aligned}
& C(f)=\frac{\operatorname{Im}(Y 11)}{2 * \Pi * \mathrm{f}} \\
& Q(f)=\frac{\operatorname{Im}(Y 11)}{\operatorname{Re}(Y 11)} \\
& \text { Return } \operatorname{Loss}(f)=10 * \log (S 11)
\end{aligned}
$$

The measurement results are reported on figure 10 for the six fluid positions described in figure 2 . It can be observed in figure 10(a) that the capacitor value increases with the fluid positions and reaches its maximum when the channel is full.

\section{(Insert figure 10)}

However, the quality factor becomes minimal when the capacitor is completely filled with deionized water as illustrated in figure 10(b). The measurement of return loss, figure 10(c), shows that the resonant frequency is maximal when the capacitor is empty and decreases continuously from $3 \mathrm{GHz}$ to $650 \mathrm{MHz}$, in response to a fluid displacement between POS0 and POS6. 


\subsection{Comparison between experimental and theoretical results:}

We have grouped in figure 11 the experimental measurements and the simulations results of the evolution of capacitance values, quality factor and resonant frequency for the six positions of DI water in fluidic channels. As shown in figure 11(a) the experimental capacitor values are close to those simulated and it is be observed that they can be tuned from $\mathrm{C}_{\min }=0.52 \mathrm{pF}$ to $\mathrm{C}_{\max }=24.8 \mathrm{pF}$, allowing a high tuning range close to $4650 \%$.

Between these extreme values, we observe also that there is a regular variation of capacitance when the water positions in channels are modified. However, results between experience and simulations for the quality factor reported in figure 11(b) show that the global behavior is preserved, but with a significant difference when the capacitor is empty.

\section{(Insert figure 11)}

On figure 11(c) are reported the results for the resonant frequency and we can note that there is some differences between measurement and simulations values but also that there is a similar evolution for each position of water. An approximate calculus shows that the resonant frequency can be tuned until $335 \%$ between Fres $=3 \mathrm{GHz}($ POS0) and Fres $=0.69 \mathrm{GHz}($ POS6).

The measured quality factor at $550 \mathrm{MHz}$ is maximal $\mathrm{Q}_{\max }=79$ when the capacitor is empty and can reach $\mathrm{Q}_{\min }=3.13$ when the channel is full.

The Table 1 resume the RF performances of our capacitor and others tunable RF MEMS capacitors presented in literature.

\section{(Insert table 1)}

\section{Conclusion:}

The device presented in this paper can be considered as another milestone associating microfluidic and RF components. This MEMS capacitor has been designed, simulated and realized by integrating some fluidic channels between its metallic electrodes. The simulation results show that there are important capacitance variations and a large range of the resonant frequency values. Moreover, the geometrical optimizations of the electrodes and also the microchannels width have been conducted; the results show that they affect significantly the capacitor performances. The complete device has been fabricated by using the classical electroplating technology associated to an SU-8 lamination process. The electrical measurements show that the capacitance value and the resonant frequency vary continuously in accordance with the different positions of deionized water in channels. To our knowledge, the range variations of capacitance measured with our device is the highest reported in specialized papers. 


\section{Acknowledgment}

This work was initiated in the framework of the cooperation between DGRS (Tunisia) and CNRS (France). The authors wish to thank Emilie Debourg for her participation in the fabrication of the microfluidic MEMS structures.

\section{References}

[1] Young D J and Boser B E 1996 A micromachined variable capacitor for monolithic low-noise VCOs Workshop Solid-State Sensor and Actuator pp 3-6

[2] Dussopt L and Rebeiz G M 2002 High-Q millimeter-wave MEMS varactors: extended tuning range and discrete-position designs Int Conf on Microwave Symposium Digest 2 pp 1205-1208

[3] Zou J Liu C Schutt-Aine J Chen J and Kang S M 2000 Development of a wide tuning range MEMS tunable capacitor for wireless communication systems Int Conf on Electron Devices Meeting pp 403-406

[4] Nieminen H Ermolov V Nybergh K Silanto S and Ryhänen T 2002 Microelectromechanical capacitors for RF applications J. Micromech. Microeng. 12 177-186

[5] Seok S Choi W and Chun K 2001 A novel linearly tunable MEMS variable capacitor $J$. Micromech. Microeng. 12 82-86

[6] Seok S Nam C and Chun K 2000 MEMS variable capacitor for one-chip if front end In International Symposium on Microelectronics and Assembly International Society for Optics and Photonics pp 26-33

[7] Gu L and Li X 2008 Rotational Driven RF Variable Capacitors With Post-CMOS Processes IEEE Electron Device Letters 29 195-197

[8] Yoon J B and Nguyen C C 2000 A high-Q tunable micromechanical capacitor with movable dielectric for RF applications Int Conf on Electron Devices Meeting pp 489-492

[10] Ghannam A Viallon C Bourrier D and Parra T 2009 Dielectric microwave characterization of the SU-8 thick resin used in an above IC process Int Conf on European Microwave Conference pp 10411044

[11] Wen C P 1969 Coplanar Waveguide: A Surface Strip Transmission Line Suitable for Nonreciprocal Gyromagnetic Device Applications" IEEE Trans. Microw. Theory Tech. 17 1087-1090 [12] Deal W 2008 Coplanar waveguide basics for MMIC and PCB design IEEE Microwave Magazine 9 120-133

[13] Dalmia S Lee S H Sundaram V Min S H Swaminathan M and Tummala R 2001 CPW high Q inductors on organic substrates Int Conf on Electrical Performance of Electronic Packaging pp 105108 
[14] Menicanin A B Ivanisevic N P Zivanov L D Damnjanovic M S Maric A M and Randjelovic D V 2014 Improved Performance of Multilayer CPW Inductors on Flexible Substrate IEEE Transactions on Magnetics 50 1-4

[15] Menicanin A B Zivanov L D Damnjanovic M S and Maric A M 2013 Low-cost CPW meander inductors utilizing ink-jet printing on flexible substrate for high-frequency applications IEEE Transactions on Electron Devices 60 827-832

[16] Samanta K K and Robertson I D 2011 Modelling and design of high performance capacitors for CPW multi-chip modules Int Conf on European Microwave Conference pp 301-304

[17] Zhou T Dai X W Cheng Z Q and Sun L L 2015 Graphene-loaded reconfigurable CPW interdigital capacitors Int Conf on Advanced Materials and Processes for RF and THz Applications pp 1-2

[18] Garg R Bahl I and Bozzi M 2013 Microstrip lines and slotlines Artech house

[19] Simons Rainee N 2001 Coplanar waveguide circuits components and systems John Wiley and Sons

[20] Entesari K and Rebeiz G M 2005 A 12-18-GHz three-pole RF MEMS tunable filter IEEE Trans. Microw. Theory Tech. $\mathbf{5 3} 2566-2571$

[21] Huang C C Chen N W Tsai H J and Chen J Y 2013 A coplanar waveguide bandwidth-tunable lowpass filter with broadband rejection IEEE Microwave and Wireless Components Letters 23 134136

[22] Lakshminarayanan B Mercier D and Rebeiz G M 2008 High-reliability miniature RF-MEMS switched capacitors IEEE Trans. Microw. Theory Tech. 56 971-981

[23] Pradhan B and Gupta B 2015 Ka-band tunable filter using metamaterials and RF MEMS varactors Journal of Microelectromechanical Systems 24 1453-1461

[24] Pinon S Diedhiou D Gue A Fabre N Prigent G Conedera V Rius E Quendo C Potelon B Favennec J and Boukabache A 2012 Development of a microsystem based on a microfluidic network to tune and reconfigure RF circuits J. Micromech. Microeng. 22074005

[25] Fulcrand R Jugieu D Escriba C Bancaud A Bourrier D Boukabache A and Gué A M 2009 Development of a flexible microfluidic system integrating magnetic micro-actuators for trapping biological species J. Micromech. Microeng. 19105019

[26] El Gmati I Calmon P Boukabache A Pons P Fulcrand R Pinon S Boussetta H Kallala M and Besbes K 2011 Fabrication and evaluation of an on-chip liquid micro-variable inductor J. Micromech. Microeng. 21025018 


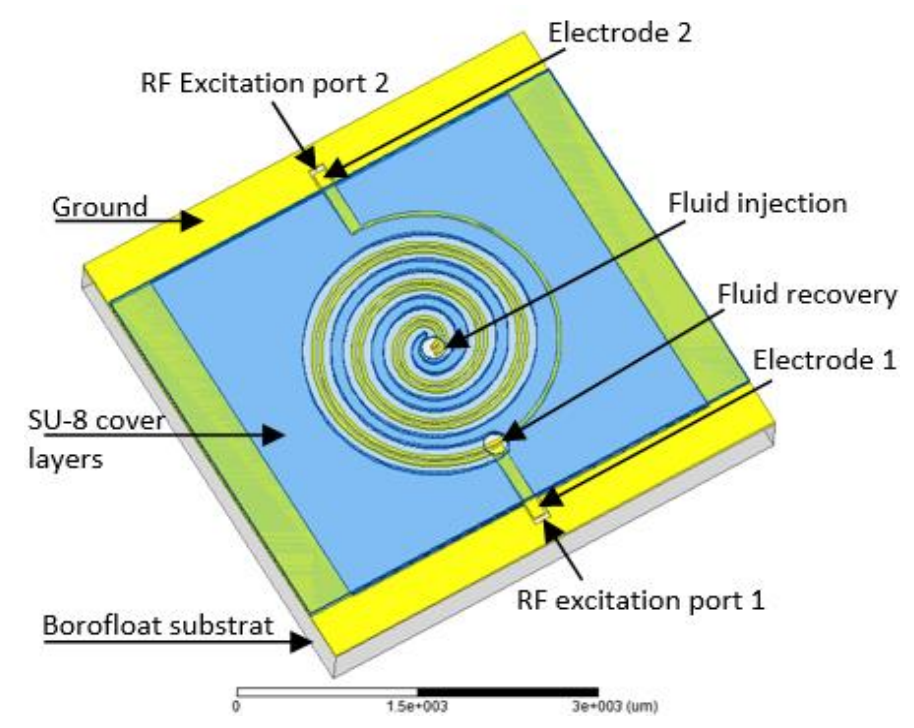

(a)

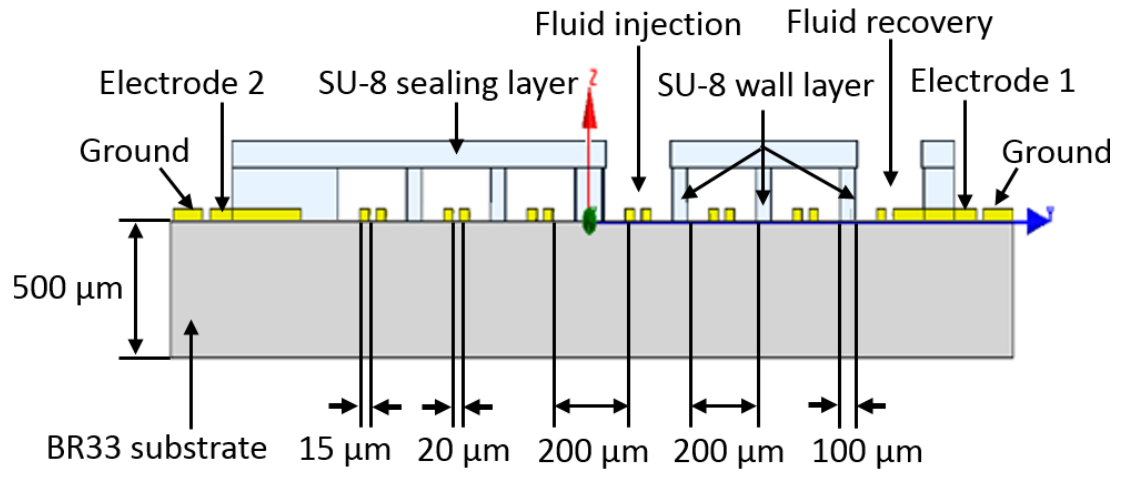

(b)

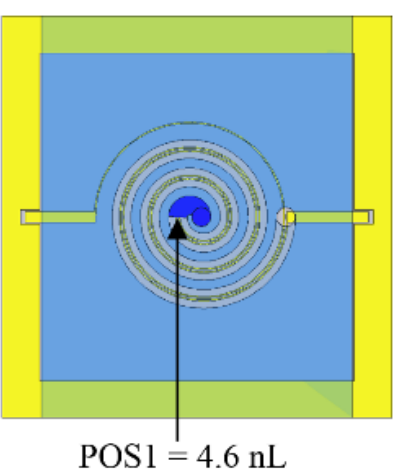

(c)

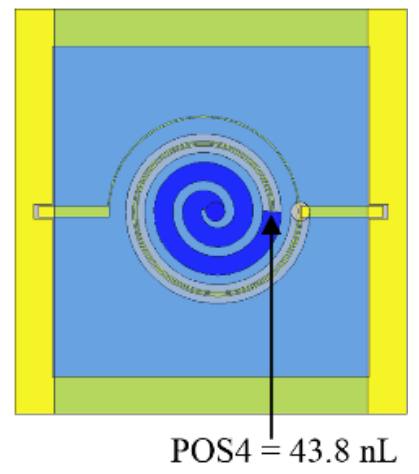

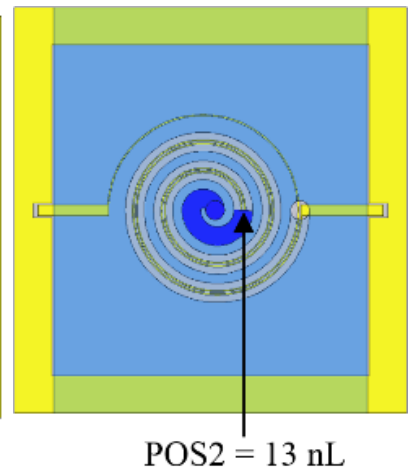

(d)

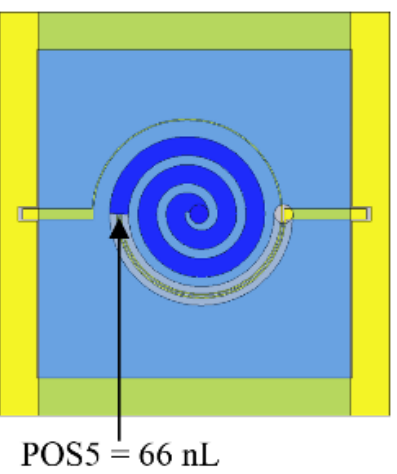

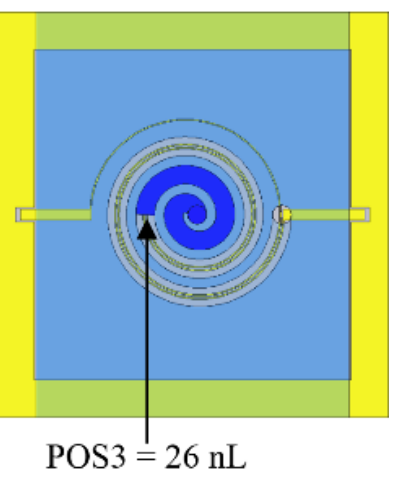

(e)

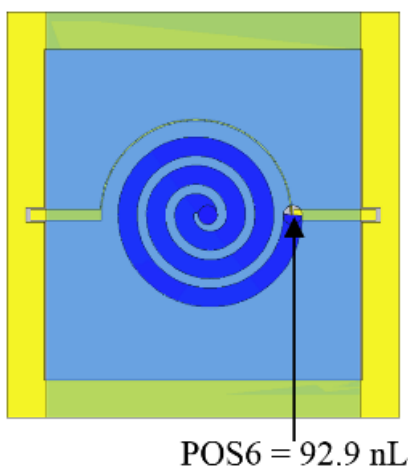


Figure 1. Different views of the proposed microfluidic capacitor: (a) and (b) tridimensional representation and cross-section of the projected capacitor; (c) to (h): positions and quantity of DI water in channel.

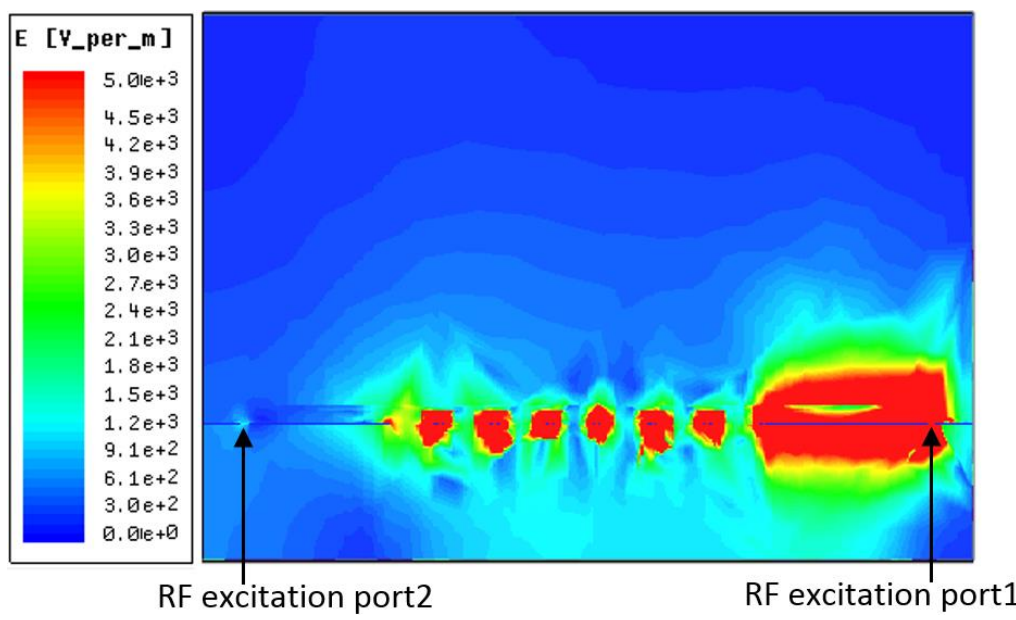

(a)

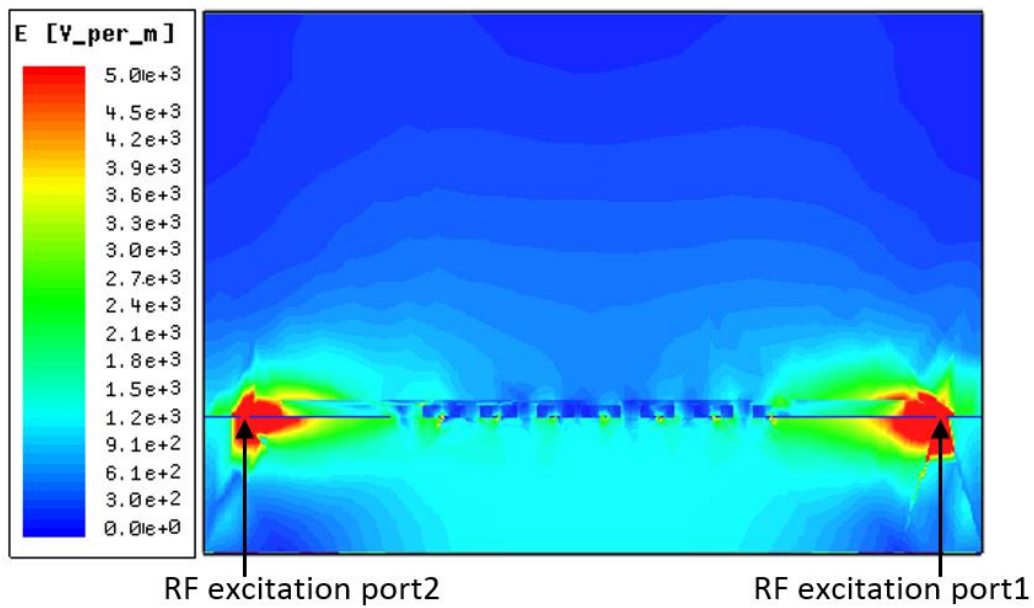

(b)

Figure 2. Cross section of the electric field distribution at $550 \mathrm{MHz}$ (a) device empty (POSO); (b) fully filled with DI water (POS6). 

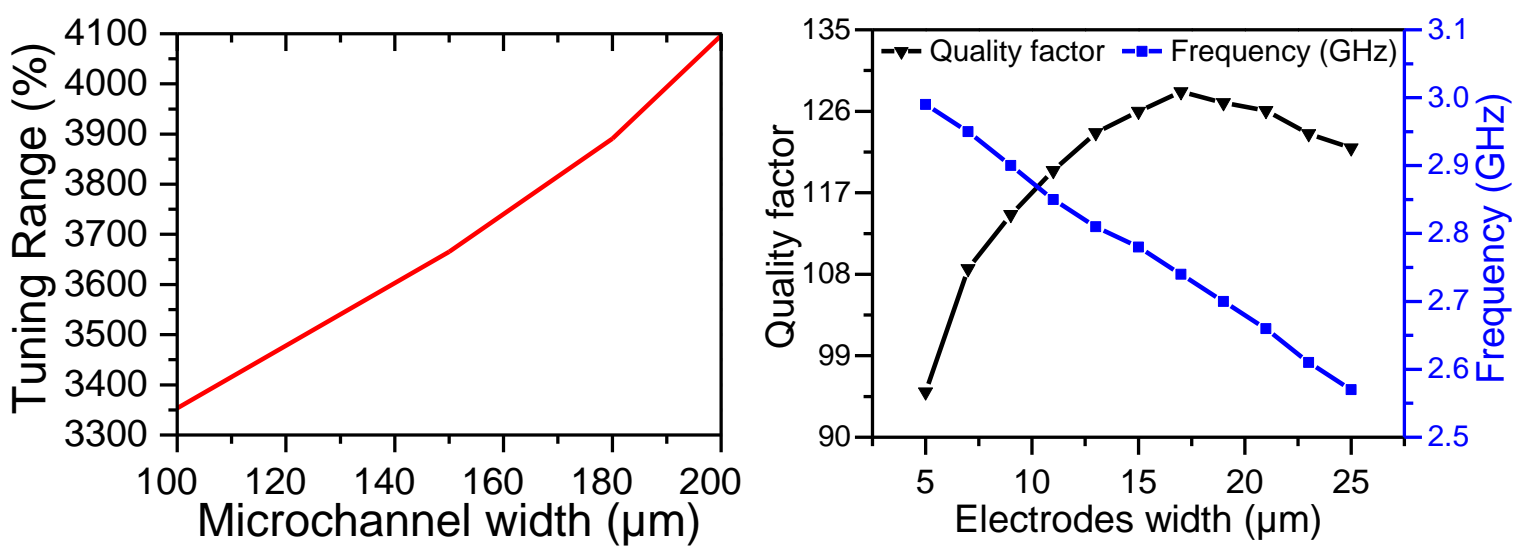

Figure 3. (a) Effect of the microchannel width variations on the device tuning range (b) Influence of the electrode's width on the quality factor and frequency responses .

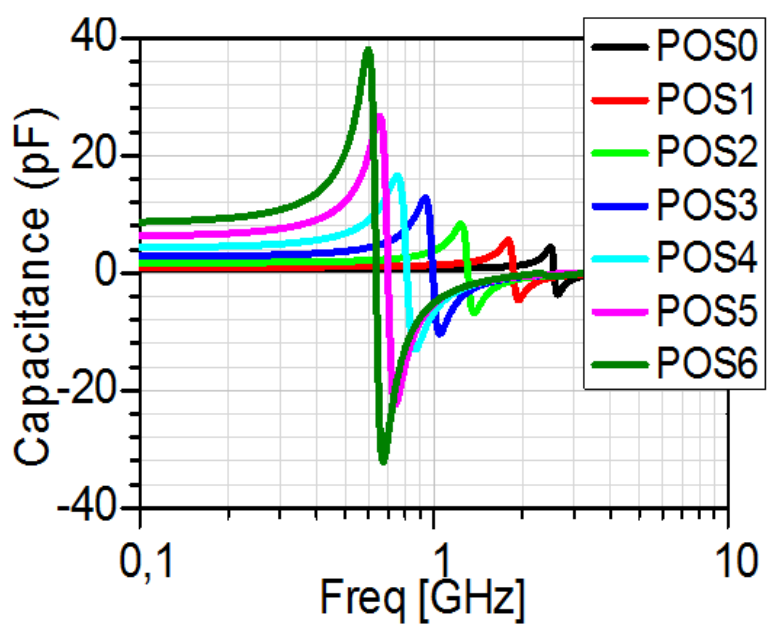

(a)

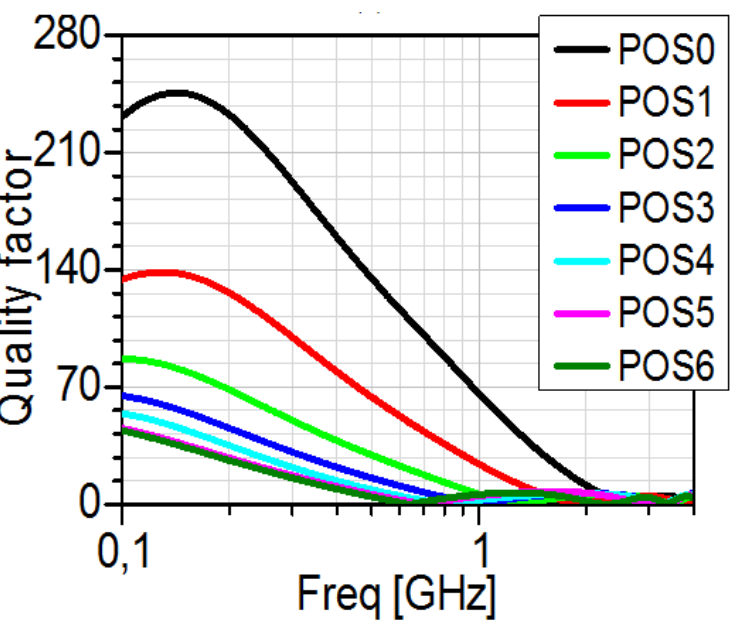

(b)

Figure 4. Theoretical curves of variations of (a) the capacitance and (b) the quality factor of the MEMS device for the six positions of deionized water between electrodes.

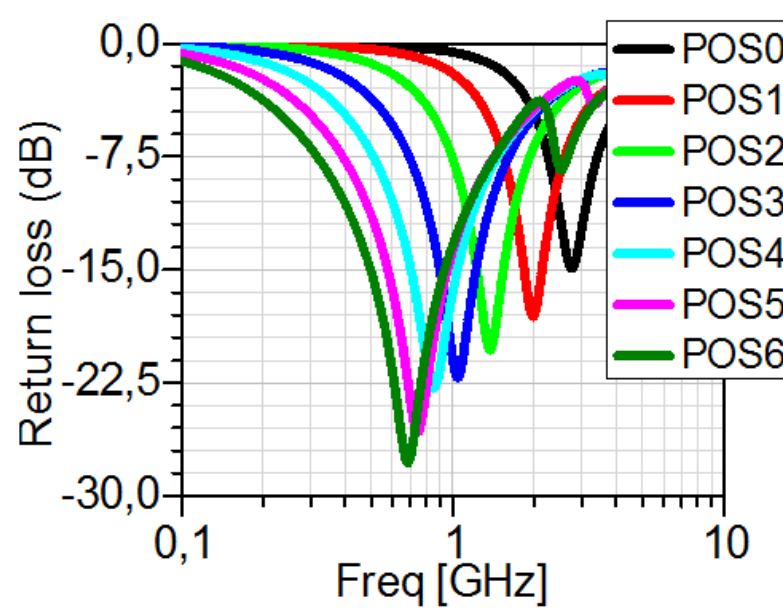

(a)

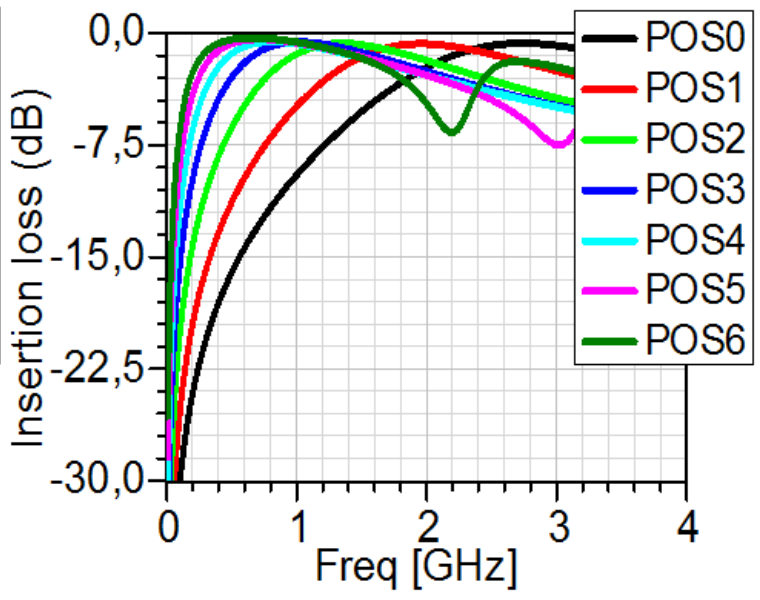

(b) 
Figure 5. Simulated (a) return loss; (b) insertion loss of the device for the six positions of deionized water.

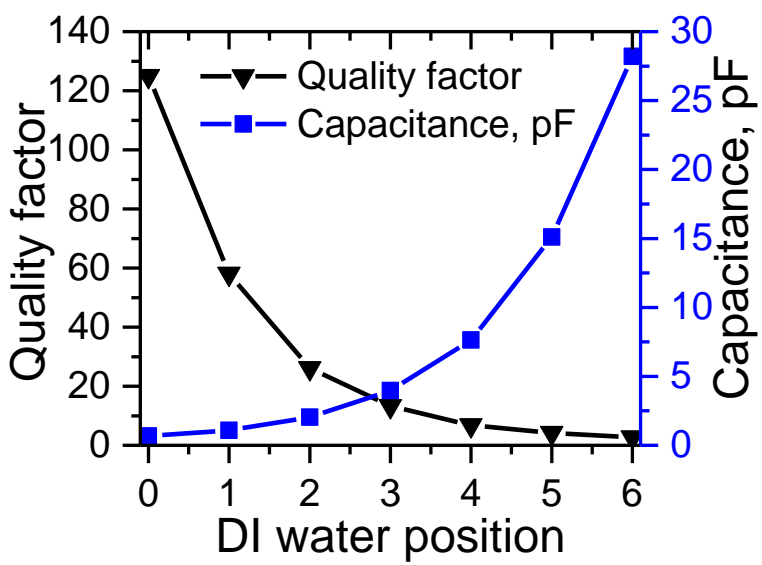

(a)

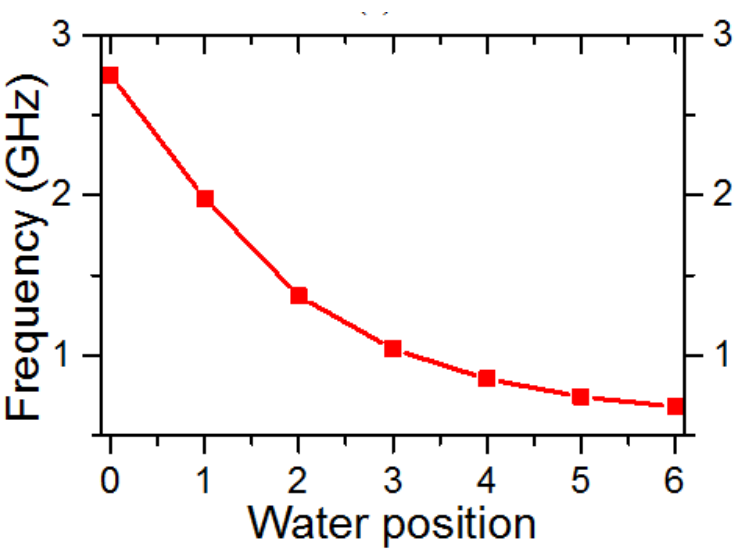

(b)

Figure 6. Simulated (a) capacitance and quality factor at $550 \mathrm{MHz}$ (b) resonant frequency, for six deionized water positions.

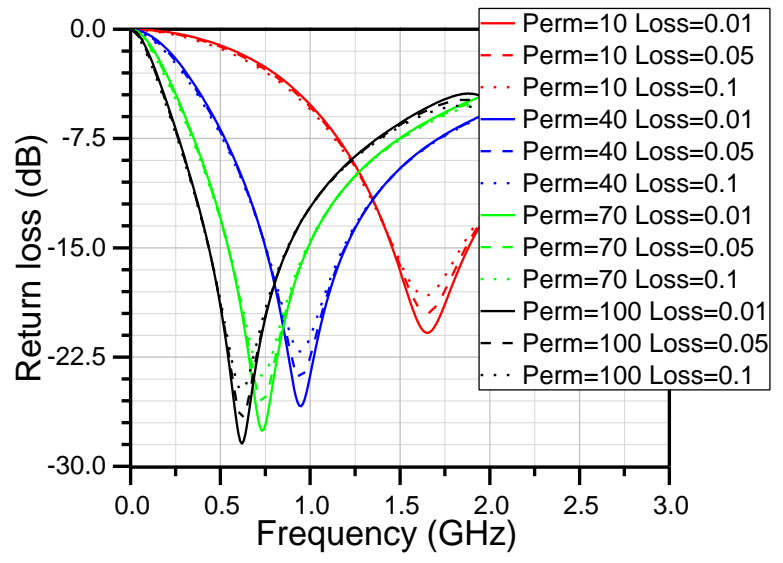

(a)

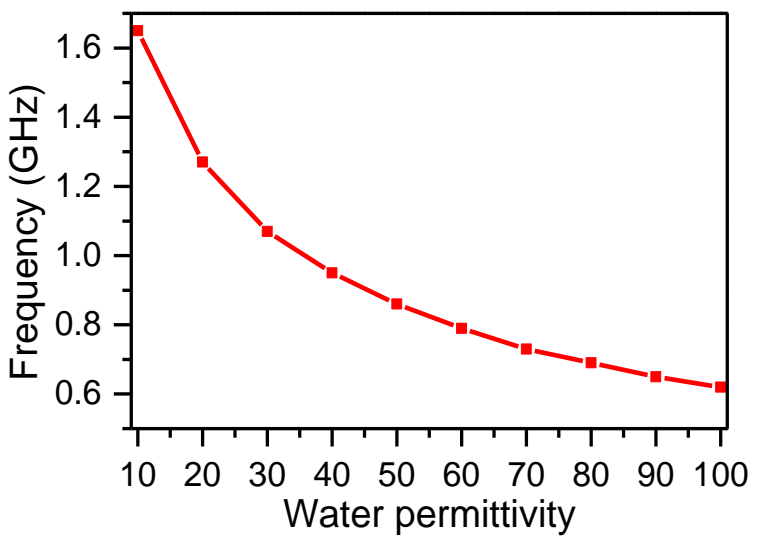

(b)

Figure 7. Simulation of (a) Return loss curves for different values of $\tan \delta$ and $\varepsilon_{r}$; and (b) frequency variation in response of $\varepsilon_{r}$. 


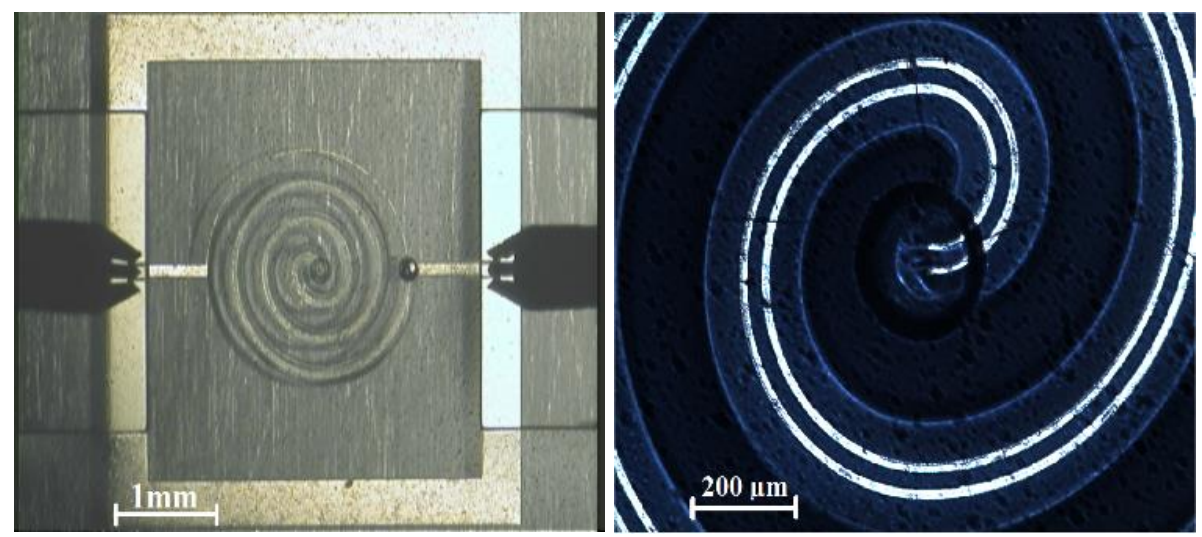

(a)

(b)

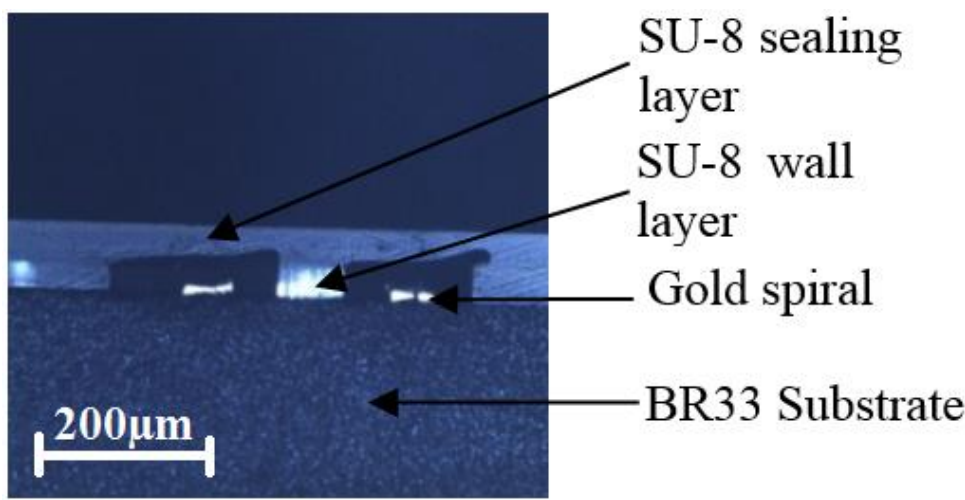

(c)

Figure 8. Photography of the MEMS device (a) under test (b) zoom of its terminal port (c) cross section of the superposed layers. 


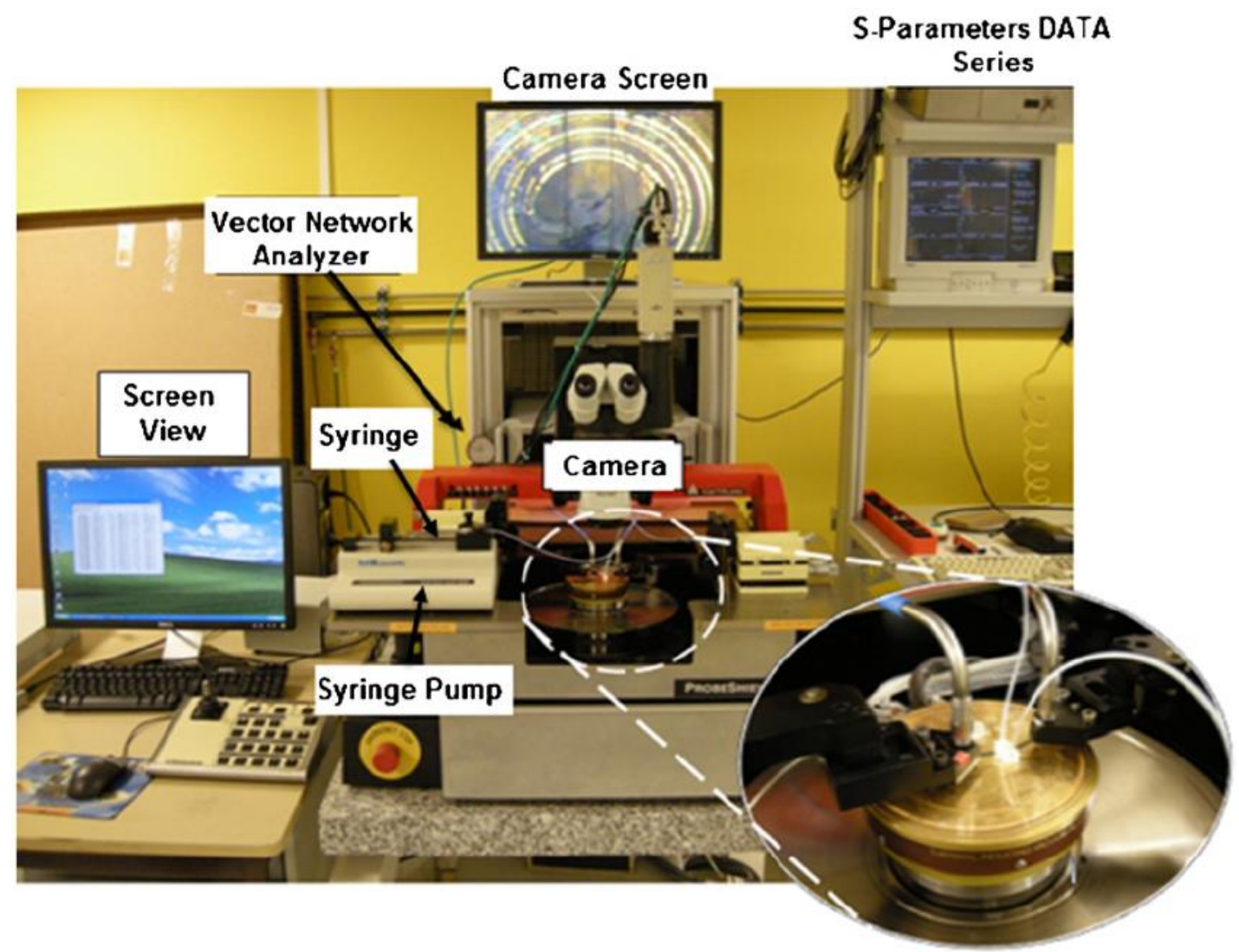

Figure 9. Specific measurement bench for frequency characterization [26].

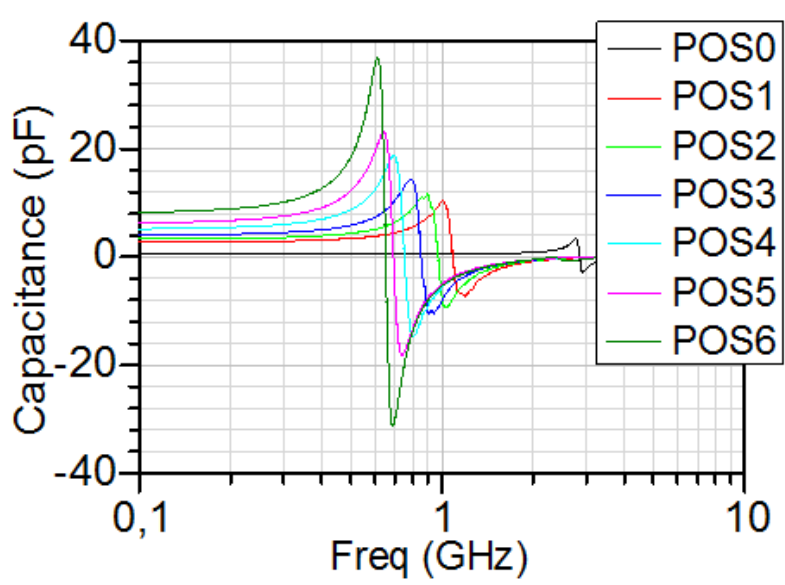

(a)

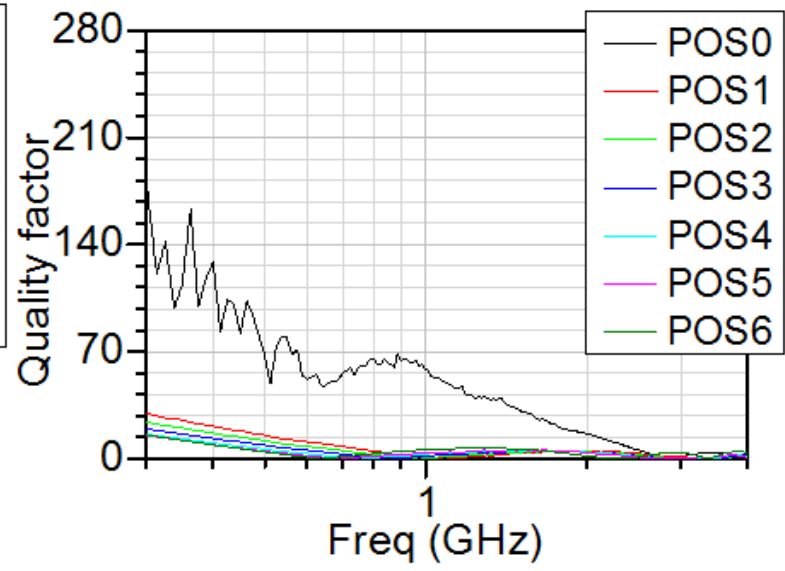

(b) 


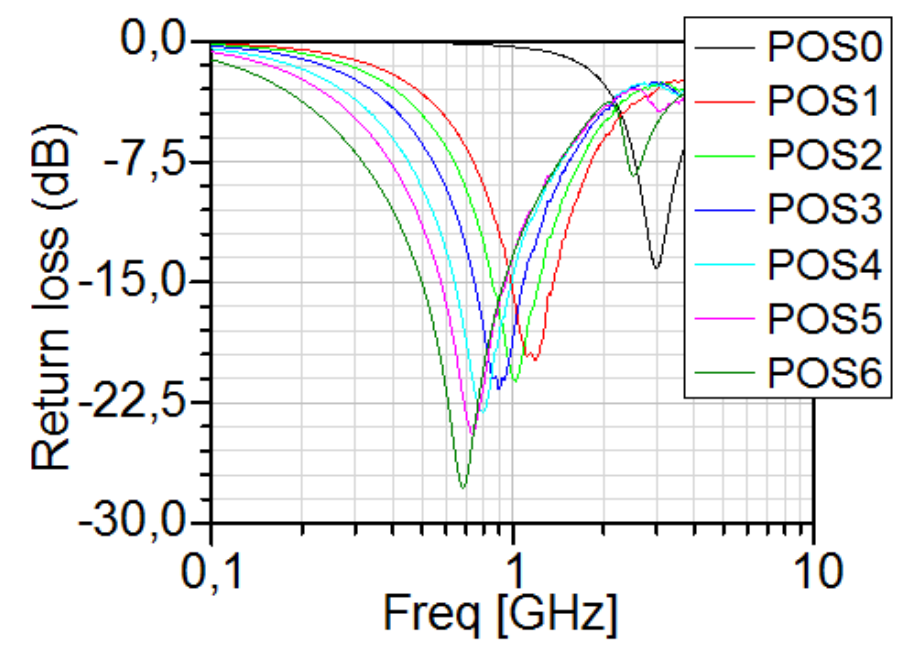

(c)

Figure 10. Experimental results for the measure of (a) Capacitance (b) quality factor (c) return loss of our devices when the channels are filled, partially or totally with deionized water.

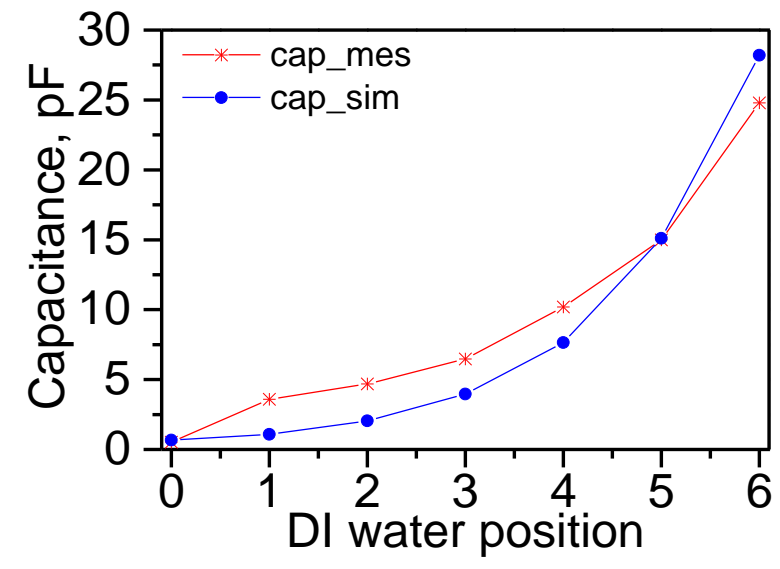

(a)

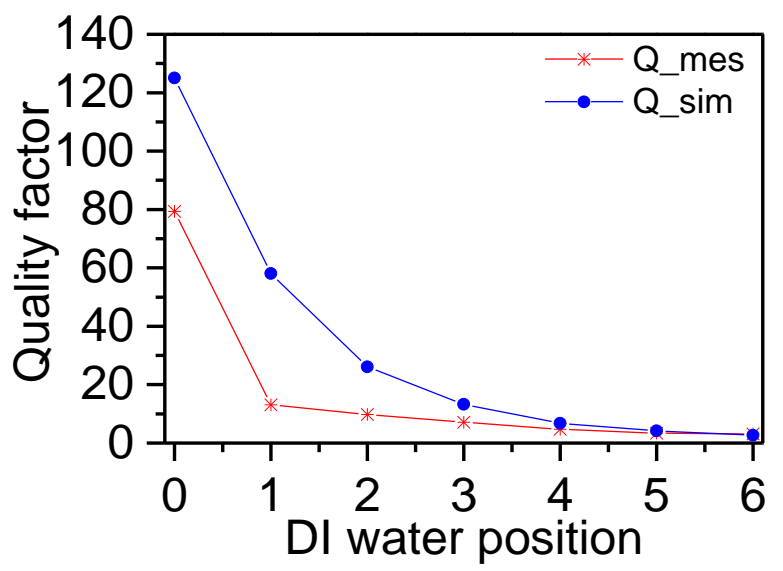

(b)

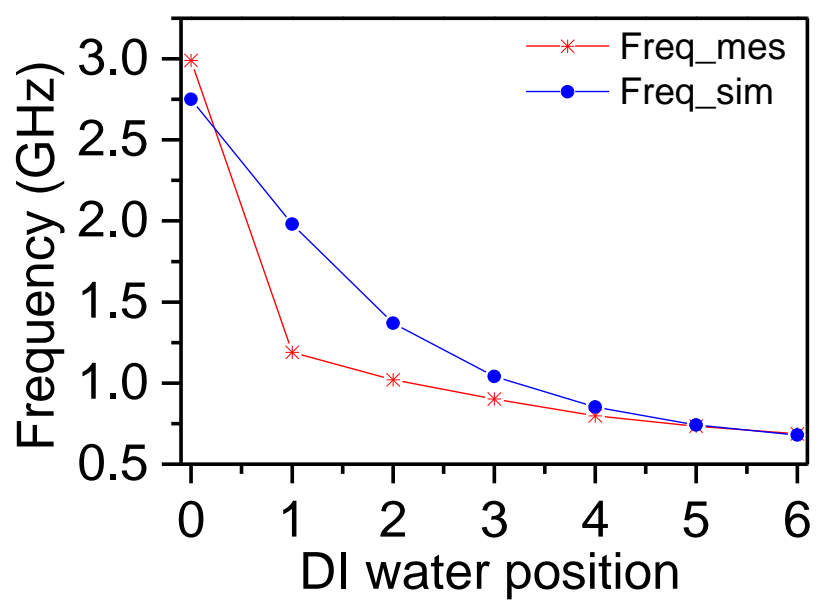

(c) 
Figure 11. Comparison between measurements and simulations of our device for the six deionized water positions in channel: (a) capacitance at $550 \mathrm{MHz}$ (b) quality factor at $550 \mathrm{MHz}$ (c) resonant frequency.

Table 1.

Comparison between tunable RF MEMS capacitors performances

\begin{tabular}{ccccc}
\hline References & Capacitance & $\begin{array}{c}\text { Tuning } \\
\text { range }\end{array}$ & $\begin{array}{c}\text { Quality } \\
\text { factor }\end{array}$ & $\begin{array}{c}\text { SRF } \\
(\mathrm{GHz})\end{array}$ \\
\hline$[1]$ & $2.11-2.46 \mathrm{pF}$ & $16.5 \%$ & $\mathrm{Q}=100$ & --- \\
{$[2]$} & $115-260 \mathrm{fF}$ & $126 \%$ & $\mathrm{Q}=100$ & 83 \\
{$[3]$} & --- & $69.8 \%$ & --- & $>10$ \\
{$[4]$} & $1.58-3.55 \mathrm{pF}$ & $125 \%$ & $\mathrm{Q}=66$ & --- \\
{$[5-6]$} & $1.27-1.4 \mathrm{pF}$ & $10 \%$ & $\mathrm{Q}=80$ & 4.35 \\
{$[7]$} & $130-270 \mathrm{fF}$ & $107 \%$ & $\mathrm{Q}=51.3$ & 9.57 \\
{$[8]$} & $1.14-1.6 \mathrm{pF}$ & $40 \%$ & $\mathrm{Q}=290$ & 19 \\
{$[9]$} & $118-551 \mathrm{fF}$ & $367 \%$ & $\mathrm{Q}=56$ & --- \\
Our work & $0.52-24.8 \mathrm{pF}$ & $4650 \%$ & $\mathrm{Q}=79$ & 3 \\
\hline
\end{tabular}

